\title{
後頭蓋窩破裂脳動脈瘤急性期手術例の検討
}

\author{
貫井 英明, 佐々木 秀夫，金子 的実 \\ 柿沢敏之, 西ヶ谷和之, 宮沢伸彦 \\ 清 水 庸夫, 保坂 力, 堀越徹*
}

\section{Early Surgery for Ruptured Vertebro-basilar Aneurysms}

Hideaki Nukui, M.D., Hideo Sasaki, M.D., Masami Kaneko, M.D., Toshiyuki Kakizawa, M.D., Kazuyuki Nishigaya, M.D., Nobuhiko Miyazawa, M.D., Tsuneo Shimizu, M.D.,

Tsutomu Hosaka, M.D.,* and Tohru HoRikoshi, M.D.*

Department of Neurosurgery, Yamanashi Medical College, Yamanashi, and

*Kanto Neurosurgical Hospital, Saitama, Japan

Summary : Although there has been a trend toward early operation for ruptured aneurysms of the anterior circulation, there have been few reports about early surgery for ruptured vertebro-basilar aneurysms.

In this paper, the result of early surgery was compared with that of delayed surgery and the timing of the operation was discussed for cases with ruptured vertebro-basilar aneurysms.

Operation was performed within seven days after the bleeding in 16 cases (grade I: three cases, II: five cases, III: five cases, IV: three cases) and over eight days in 48 cases (grade I: 29 cases, Ia: 11 cases, III: five cases, IV: three cases).

The overall results indicated that two patients (13\%) remained in poor condition, three patients (19\%) expired during early surgery, eight patients (17\%) were disabled and three patients $(6 \%)$ died during delayed surgery. Cases of death during early surgery seemed to be frequent, but these patients were in poor condition before the operation (Hunt and Kosnik's grade III: One case, IV: two cases).

When examining the grade I and II cases, only one case with fusiform aneurysm of the vertebral artery, out of eight cases, was in poor condition and no case expired during early surgery. Two cases out of 29 were disabled and one died during delayed surgery.

A good or excellent outcome was obtained in $88 \%$ of early surgery cases and $90 \%$ in delayed surgery.

Concerning the grade III and IV cases, one out of eight cases was poor and three cases died in early surgery. Four out of eight cases was disabled and one died in delayed surgery.

A good or excellent outcome was obtained in $50 \%$ of early surgery cases and $38 \%$ of delayed surgery.

Therefore, the overall results viewed from the point of the clinical grade of the patient before the operation are the same for both groups.

From these results it can be seen that early surgery is indicated in cases with ruptured vertebrobasilar aneurysms as in cases with other aneurysms, except for cases with fusiform aneurysms of the vertebral artery.
Key words :

- ruptured aneurysms

- vertebro-basilar system

- early operation

- delayed operation

- surgical result 


\section{はじめに}

破裂脳動脈瘤に対する直達手術は, 近年出血後急性期に 行われることが多いが，椎骨脳底動脈瘤 (VB AN)に関し ては，出血後慢性期まで手術を待機するのが一般的である 1)6)8)9).

これは VB AN が脳の深部に存在するため, 急性期手術 の際に脳の圧排が強くなり，また術中動脈瘤破裂が生じた 場合，止血困難である等の理由によるものと考えられる.

一方，本動脈瘤では手術待機中の再出血による悪化，死 亡が高率であることが報告されており ${ }^{3) 6)}$ ，手術時の技術 的問題が解決されれば, VB ANにおいても出血後早期に 手術を行った方が良いと思われる.

われわれは最近 VB AN に対し可及的早期に手術を行う 方針をとってきたので, 従来経験した症例において手術時 期別の治療成績を比較し，本動脈瘤の手術時期を検討した.

\section{症例}

検討の対象とした症例はVB AN 64例で，手術時期は出
血後 3 日以内 10 例， $4 \sim 7$ 日 6 例，8１4日 2 例， 15 日以 後46例である.

動脈瘤の存在部位および Hunt らの術前 grade（Table 1) は，3 日以内手術例では脳底動脈末梢部 (BA-Bif AN) 6 例, 後下小脳動脈分岐部(PICA AN) 2 例, 上小脳動脈分 岐部（BA-SCA AN）1 例, 椎骨動脈 (VA AN) 1 例で, grade I 2 例, II 5 例, III 1 例, IV 2 例である.

出血後 4〜 7 日手術例では, BA-Bif AN 3 例, PICA AN 2 例, BA-SCA AN 1 例で, grade I 1 例, III 4 例, IV 1 例であり，8～14日手術例では BA-Bif AN 1 例, 後 大脳動脈末梢部動脈瘤 $\left(\mathrm{P}_{2} \mathrm{AN}\right) 1$ 例で, いずれも grade I である。

15日以後手術例は, BA-Bif AN 20例, PICA AN 12例, BA-SCA AN 4 例, VA AN 4 例, 後交通動脈後大脳動脈 接合部動脈瘤 (PC-PCom AN) 4 例, $\mathrm{P}_{2} \mathrm{AN} 1$ 例, 前下小 脳動脈分岐部動脈瘤 (AICA AN) 1 例であり, 術前 grade は I 27例，Ia 11例，III 5 例，IV 3 例であった。

手術は, BA-Bif AN, BA-SCA AN, PC-PCom AN お よびAICA AN では一側 pterional approach で, PICA

Table 1 Number of cases with ruptured vertebro-basilar aneurysms

\begin{tabular}{|c|c|c|c|c|c|c|}
\hline \multirow{2}{*}{$\begin{array}{l}\text { Timing of op. } \\
\& \text { site of op. }\end{array}$} & \multicolumn{5}{|c|}{ Clinical grade just before op. } & \multirow{2}{*}{ Total } \\
\hline & I & Ia & II & III & IV & \\
\hline Within 3 days & 2 & $\mathbf{0}$ & 5 & 1 & 2 & 10 \\
\hline BA-Bif & 1 & 0 & 3 & 1 & 1 & 6 \\
\hline PICA & 1 & 0 & 0 & 0 & 1 & 2 \\
\hline BA-SCA & 0 & 0 & 1 & 0 & 0 & 1 \\
\hline VA & 0 & 0 & 1 & 0 & 0 & 1 \\
\hline 4-7 days & 1 & $\mathbf{0}$ & $\mathbf{0}$ & 4 & 1 & 6 \\
\hline BA-Bif & 1 & 0 & 0 & 2 & 0 & 3 \\
\hline PICA & 0 & 0 & 0 & 2 & 0 & 2 \\
\hline BA-SCA & 0 & 0 & 0 & 0 & 1 & 1 \\
\hline 8-14 days & 2 & $\mathbf{0}$ & 0 & $\mathbf{0}$ & 0 & 2 \\
\hline BA-Bif & 1 & 0 & 0 & 0 & 0 & 1 \\
\hline $\mathrm{P}_{2}$ & 1 & 0 & 0 & 0 & 0 & 1 \\
\hline Over 15 days & 27 & 11 & $\mathbf{0}$ & 5 & 3 & 46 \\
\hline BA-Bif & 11 & 3 & 0 & 4 & 2 & 20 \\
\hline PICA & 6 & 5 & 0 & 0 & 1 & 12 \\
\hline BA-SCA & 2 & 1 & 0 & 1 & 0 & 4 \\
\hline VA & 3 & 1 & 0 & 0 & 0 & 4 \\
\hline PC-PCom & 4 & 0 & 0 & 0 & 0 & 4 \\
\hline $\mathrm{P}_{2}$ & 0 & 1 & 0 & 0 & 0 & 1 \\
\hline AICA & 1 & 0 & 0 & 0 & 0 & 1 \\
\hline Total & $32(50 \%)$ & $11(17 \%)$ & $5(8 \%)$ & $10(16 \%)$ & $6(9 \%)$ & 64 \\
\hline
\end{tabular}

* BA-Bif: Basilar artery bifurcation, PICA: Posterior inferior cerebellar artery, BA-SCA: Basilar artery-superior cerebellar artery junction, VA: Vertebral artery, $\mathrm{P}_{2}$ : $\mathrm{P}_{2}$ segment of posterior cerebral artery, PC-PCom: Posterior cerebral-Posterior communicating artery junction, AICA: Anterior inferior cerebellar artery 
AN，VA AN に対しては suboccipital approach で， $\mathrm{P}_{2}$ ANでは subtemporal approach で施行した.

手術に際しては，髄液を十分吸引するとともにクモ膜を 広く剥離して脳圧排の影響を少なくし, 可及的早期に親動 脈近位部を確保して, 必要に応じ短時間の血流遮断を用い た。

結局, VA の fusiform AN 4 例で coating, 1 例で proximal ligation, AICA AN および BA-Bif AN の各 1 例で coating を行った以外，57例では clipping を施行した.

また術中動脈瘤破裂は, 出血後 3 日以内手術例で 1 例, $4 \sim 7$ 日例で 2 例, 15日以後手術例で 3 例に認められ, 血 流一時遮断は 3 日以内手術例で 3 例, $4 \sim 7$ 日例で 3 例, 15日以後例で 12 例に用いたが， 1 回の血流遮断の時間は 3 例 ( 7 分, 8 分, 13分)を除く例ではすべて 5 分以内であっ た。

\section{結 果}

\section{1. 手術後成樍}

手術後成績は, 退院時あるいは手術後 3 か月での臨床症 候を術前症候と比較し，改善あるいは同様，悪化，死亡の 3 群に分類した (Table 2,3).

まず出血後 3 日以内手術例10例では, grade II の 2 例が 悪化し, IVの 1 例が死亡した.

悪化した 2 例のうち 1 例は, 69歳, BA-SCA AN で,
Table 2 Operative results at discharge in cases with ruptured vertebro-basilar aneurysms

\begin{tabular}{ccccc}
\hline \multirow{2}{*}{$\begin{array}{c}\text { Timing of op. } \\
\text { \& clinical grade }\end{array}$} & \multicolumn{3}{c}{ Operative result at discharge } & Totel \\
\cline { 2 - 4 } & $\begin{array}{c}\text { Improved or } \\
\text { stationary }\end{array}$ & $\begin{array}{c}\text { Deterio- } \\
\text { rated }\end{array}$ & Dead & \\
\hline Within 3 days & $\mathbf{7}$ & $\mathbf{2}$ & $\mathbf{1}$ & $\mathbf{1 0}$ \\
I & 2 & 0 & 0 & 2 \\
II & 3 & 2 & 0 & 5 \\
III & 1 & 0 & 0 & 1 \\
IV & 1 & 0 & 1 & 2 \\
4-7 days & $\mathbf{4}$ & $\mathbf{0}$ & $\mathbf{2}$ & $\mathbf{6}$ \\
I & 1 & 0 & 0 & 1 \\
III & 3 & 0 & 1 & 4 \\
IV & 0 & 0 & 1 & 1 \\
8-14 days & $\mathbf{2}$ & $\mathbf{0}$ & $\mathbf{0}$ & $\mathbf{2}$ \\
I & 2 & 0 & 0 & 2 \\
Over 15 days & $\mathbf{4 1}$ & $\mathbf{4}$ & $\mathbf{1}$ & $\mathbf{4 6}$ \\
I & 23 & 3 & 1 & 27 \\
Ia & 10 & 1 & 0 & 11 \\
III & 5 & 0 & 0 & 5 \\
IV & 3 & 0 & 0 & 3 \\
\hline Total & $54(84 \%)$ & $6(9 \%)$ & $4(6 \%)$ & 64 \\
\hline
\end{tabular}

出血後28時間で clipping を施行し, 術後は経過良好であ ったが，術後14日目に生じた paroxysmal atrial tachycardia に伴う低血圧により意識障害を生じた例である.

Table 3 Deteriorated and dead cases with ruptured vertebro-basilar aneurysms after the operation

\begin{tabular}{|c|c|c|c|c|c|c|c|c|}
\hline $\begin{array}{l}\text { Case } \\
\text { No. }\end{array}$ & $\begin{array}{l}\text { Age \& } \\
\text { sex }\end{array}$ & $\begin{array}{l}\text { Site of } \\
\text { aneurysm }\end{array}$ & $\begin{array}{l}\text { Clinical } \\
\text { grade }\end{array}$ & $\begin{array}{l}\text { Interval } \\
\text { between } \\
\text { SAH \& op. }\end{array}$ & $\begin{array}{l}\text { Operative } \\
\text { result }\end{array}$ & $\begin{array}{l}\text { Clinical signs } \\
\text { afer op. }\end{array}$ & $\begin{array}{l}\text { Causes of } \\
\text { deterioration }\end{array}$ & $\begin{array}{l}\text { Other } \\
\text { remarks }\end{array}$ \\
\hline 1 & 56.M & $\mathrm{BA}$ & IV & 22 hours & dead & $\begin{array}{l}\text { disturbance of } \\
\text { consciousness }\end{array}$ & primary brain damage & pneumonia \\
\hline 2 & 69. F & SCA & II & 28 hours & $\begin{array}{l}\text { deterio- } \\
\text { rated }\end{array}$ & $\begin{array}{l}\text { disturbance of } \\
\text { consciousness }\end{array}$ & $\begin{array}{l}\text { incidental disease } \\
\text { (hypotension with } \text { PAT }^{3} \text { ) }\end{array}$ & \\
\hline 3 & $55 . \mathrm{M}$ & VA & II & 38 hours & $\begin{array}{l}\text { deterio- } \\
\text { rated }\end{array}$ & $\begin{array}{l}\text { disturbance of } \\
\text { consciousness }\end{array}$ & $\begin{array}{l}\text { surgical procedure } \\
\text { (emboli from aneurysm) }\end{array}$ & $\begin{array}{l}\text { fusiform } \\
\text { aneurysm }\end{array}$ \\
\hline 4 & 64. F & BA & III & 4 days & dead & $\begin{array}{l}\text { disturbance of } \\
\text { consciousness }\end{array}$ & vasospasm & \\
\hline 5 & 43.M & SCA & IV & 4 days & dead & $\begin{array}{l}\text { disturbance of } \\
\text { consciousness }\end{array}$ & vasospasm & \\
\hline 6 & 27.M & PC-PCom & I & 30 days & dead & $\begin{array}{l}\text { disturbance of } \\
\text { consciousness }\end{array}$ & $\begin{array}{l}\text { surgical procedure } \\
\text { (disturb. of B.F.)*1 }\end{array}$ & $\begin{array}{l}\text { occlusion of } \\
\text { cervical } \mathrm{CA}^{* 2}\end{array}$ \\
\hline 7 & 45.M & $\mathrm{BA}$ & I & 19 days & $\begin{array}{l}\text { deterio- } \\
\text { rated }\end{array}$ & $\begin{array}{l}\text { disturbance of } \\
\text { consciousness }\end{array}$ & vasospasm & \\
\hline 8 & 70.M & BA & I & 26 days & $\begin{array}{l}\text { deterio- } \\
\text { rated }\end{array}$ & himiplegia & $\begin{array}{l}\text { surgical procedure } \\
\text { (occlusion of PCA) }\end{array}$ & $\begin{array}{l}\text { high position } \\
\text { of } \mathrm{BA}\end{array}$ \\
\hline 9 & 45. F & PICA & I & 37 days & $\begin{array}{l}\text { deterio- } \\
\text { rated }\end{array}$ & $\begin{array}{l}\text { lower cranial } \\
\text { nerve palsy }\end{array}$ & surgical procedure & \\
\hline 10 & 44.M & PICA & Ia & 63 days & $\begin{array}{l}\text { deterio- } \\
\text { tated }\end{array}$ & $\begin{array}{l}\text { cerebellar } \\
\text { signs }\end{array}$ & surgical procedure & \\
\hline
\end{tabular}

*1: disturbance of blood flow

*2. carotid artery

*3: paroxysmal atrial tachycardia 
他の 1 例は, 55歳, VA fusiform AN で, 出血後38時間 で手術を行ったが, 術中操作により動脈瘤壁からの血栓が 脳幹への穿通枝を閉塞し, 意識障害をきたしたと考えられ た例である。

死亡例の 1 例は, 56歳, BA-Bif AN で, 出血後22時間 で clipping を行ったが, 意識障害の軽度改善を示したの みで, その後肺炎, DIC を合併し, 術後78日目に死亡し た。

出血後 $4 \sim 7$ 日手術例では, grade III, IV の各 1 例が, 5 日および 4 日後血管攣縮による急激な症状悪化をきたし， 術後 6 日および 8 日目に死亡した.

8～14日手術例では悪化，死亡を認めなかったが，15日 以後手術例では悪化 4 例, 死亡 1 例で, いずれも grade I の例であった.

悪化 4 例中 2 例はPICA AN で，手術操作による下部 脳神経症状および小脳症状を認めた。

他の 1 例は, 70歳, BA-Bif AN で, 動脈瘤頸部が clivus 上端より約 $2 \mathrm{~cm}$ 上方に存在し，このため clipping 施行 時に対側 PCAの確認が不十分で, PCAの閉塞をきたし 片麻痺を生じた

残りの 1 例は, 出血後19日目に手術を施行した BA-Bif AN で，術中の静脈血流入によると思われる脳血管攣縮が 対側内頸動脈領域に生じ, 術後 3 日目より意識障害, 麻痺 をきたした。

死亡例は同側内頸動脈閉塞を伴った grade I の PCPCom AN で, 出血後30日で clipping を施行したが, 手術 操作により PCom A の血流障害をきたし, 術後意識障害, 片麻痺を生じて，52日目に敗血症を合併し死亡した ${ }^{22}$.

術中動脈瘤破裂および血流一時遮断の有無は, 術後悪 化・死亡に関係なかった。

\section{2. 長期追跡調查結果}

術後生存例での 6 か月以上の追跡調査結果を, excellent: 術前と同様の生活可能, good: 軽度神経症状あるも介 助なしで日常生活可能, fair: 神経症状のため日常生活に 介助が必要, poor: 日常生活不能, dead: 死亡, に分類し, excellent, goodを結果良好例，それ以外を結果不良例と した (Table 4,5).

出血後 3 日以内手術例では, 術後悪化を示したVA fusiform AN が poorである以外, 他の 8 例はすべて結果 良好であった。

4〜 7 日手術例では, grade III の 1 例が術前からの意識 障害が残存し poorであり，8～14日手術例 2 例はいずれ も結果良好であった。

出血後15日以後手術例45例では, VA fusiform AN に proximal ligation を行った 1 例が 10 か後再出血で死亡, grade III の BA-Bif AN が意識障害が改善せず，肺炎を合 併して死亡した.

また術後悪化した grade I の BA-Bif AN 2 例が poor で, PICA AN の Ia 2 例, IV 1 例, BA-Bif AN のIII 2 例, IV 1 例の計 6 例が, 術前からの神経症候や意識障害のため poorであった.

結局, 手術後死亡例と長期追跡調査結果を加えた手術成 績における結果不良例は, 出血後 3 日以内手術例 10 例中 2 例, 4〜 7 日手術例 6 例中 3 例, 8〜14日手術例ではなく, 15日以後手術例46例中11例である (Table 6).

その原因は，3 日以内手術例では primary brain damage (PBD) 1 例, 手術操作 1 例, 4〜 7 日例では血管攣縮 (VS) 2 例, PBD 1 例, 15日以後例では PBD 7 例, 手術 操作 3 例, VS 1 例であった(Table 7).

\section{考案}

前述のごとくVB AN の手術は他部位動脈瘤とは異なり， 現在なお出血後慢性期になってから行われており，その手 術成績は他部位動脈瘤に比べやや悪いとする報告が多い4) 6) 9).

これは VB AN の存在部位が深部で, 術野が深くて狭く, 周囲に重要な神経組織, 血管が存在することから, 脳の圧 排を含む手術操作による合併症を生じやすく, control 困 難な術中動脈瘤破裂をきたしやすいため，他部位動脈瘤の 手術に比べ高度の技術を要するためと考えられている ${ }^{1) 5}$ 6) 8) 9)

われわれの症例でも VB ANでの overall surgical result は, 出血後 8 日以後手術例では他部位動脈瘤に比べ結果良 好例が有意に少なかった (Table 8, $\left.\chi^{2}=6.00, p<0.02\right)$.

しかし VB AN における慢性期手術例での結果不良例は 術前状態の悪い例に多いと報告されており ${ }^{1) 5)}$ ，われわれ の検討でもほぼ同様の結果がえられた.

すなわち，追跡調查時に fair〜 poorであった結果不良 例 8 例中 6 例 (grade Ia 2 例, III 2 例, IV 2 例) が術前の神 経症候残存例で, 手術操作が原因である例は grade I の 2 例にすぎない.

また死亡例 3 例では，その治療法に問題のあるVAの fusiform AN を除くと，2 例中 1 例が手術操作による死亡 例であり，手術操作そのものによる悪化・死亡例はそう多 くはない.

さらにこれら手術操作による結果不良例は，いずれも術 者の経験が少ない時期の例であり，ある程度手術手技に習 熟すれば，VB ANでも手術操作による悪化例は減少させ ることができると考えられる5).

われわれは出血後慢性期例において VB AN の手術手技 にある程度習熟してから，急性期手術を開始したが，VA 
Table 4 Follow-up results in cases with ruptured vertebro-basilar aneurysms

\begin{tabular}{ccccccc}
\hline \multirow{2}{*}{$\begin{array}{c}\text { Timing of op. \& } \\
\text { clinical grade }\end{array}$} & \multicolumn{3}{c}{ Follow-up result } & Total \\
\cline { 2 - 5 } Within 3 days & $\mathbf{6}$ & $\mathbf{2}$ & $\mathbf{0}$ & $\mathbf{1}$ & $\mathbf{0}$ & $\mathbf{9}$ \\
I & 2 & 0 & 0 & 0 & 0 & 2 \\
II & 3 & 1 & 0 & 1 & 0 & 5 \\
III & 1 & 0 & 0 & 0 & 0 & 1 \\
IV & 0 & 1 & 0 & 0 & 0 & 1 \\
4-7 days & $\mathbf{3}$ & $\mathbf{0}$ & $\mathbf{0}$ & $\mathbf{1}$ & $\mathbf{0}$ & $\mathbf{4}$ \\
I & 1 & 0 & 0 & 0 & 0 & 1 \\
III & 2 & 0 & 0 & 1 & 0 & 3 \\
8-14 days & $\mathbf{2}$ & $\mathbf{0}$ & $\mathbf{0}$ & $\mathbf{0}$ & $\mathbf{0}$ & $\mathbf{2}$ \\
I & 2 & 0 & 0 & 0 & 0 & 2 \\
Over 15 days & $\mathbf{3 3}$ & $\mathbf{2}$ & $\mathbf{0}$ & $\mathbf{8}$ & $\mathbf{2}$ & $\mathbf{4 5}$ \\
I & 24 & 0 & 0 & 2 & 0 & 26 \\
Ia & 6 & 2 & 0 & 2 & 1 & 11 \\
III & 2 & 0 & 0 & 2 & 1 & 5 \\
IV & 1 & 0 & 0 & 2 & 0 & 3 \\
\hline Total & $44(73 \%)$ & $4(7 \%)$ & 0 & $10(17 \%)$ & $2(3 \%)$ & 60 \\
\hline
\end{tabular}

Table 5 Disabled and dead cases with ruptured vertebro-basilar aneurysms at follow-up study

\begin{tabular}{|c|c|c|c|c|c|c|c|}
\hline $\begin{array}{l}\text { Case } \\
\text { No. }\end{array}$ & $\underset{\text { sex }}{\text { Age \& }}$ & $\begin{array}{c}\text { Site of } \\
\text { aneurysm }\end{array}$ & $\begin{array}{l}\text { Clinical } \\
\text { grade }\end{array}$ & $\begin{array}{c}\text { Interval } \\
\text { between } \\
\text { SAH \& op. }\end{array}$ & $\begin{array}{l}\text { Follow-up } \\
\text { result }\end{array}$ & $\begin{array}{l}\text { Clinical signs } \\
\text { at follow-up }\end{array}$ & $\begin{array}{l}\text { Causes of } \\
\text { disability } \\
\& \text { death }\end{array}$ \\
\hline 1 & $55 . \mathrm{M}$ & $\begin{array}{c}\text { VA } \\
\text { (fusiform) }\end{array}$ & II & 38 hours & poor & akinetic mutism & $\begin{array}{l}\text { surgical procedure } \\
\text { (embolization) }\end{array}$ \\
\hline 2 & 67.M & PICA & III & 7 days & poor & $\begin{array}{l}\text { disturbance of } \\
\text { consciousness }\end{array}$ & primary damage \\
\hline 3 & 45.M & BA & I & 19 days & poor & $\begin{array}{l}\text { hemiparesis, } \\
\text { aphasia }\end{array}$ & vasospasm \\
\hline 4 & 70.M & BA & I & 26 days & poor & hemiplegia & $\begin{array}{l}\text { surgical procedure } \\
\text { (occlusion of PCA) }\end{array}$ \\
\hline 5 & 56. F & PICA & Ia & 74 days & poor & hemiplegia & primary damage \\
\hline 6 & 58. $\mathrm{F}$ & PICA & Ia & 107 days & poor & $\begin{array}{l}\text { hemiparesis, } \\
\text { aphasia }\end{array}$ & primary damage \\
\hline 7 & 43.M & $\mathrm{BA}$ & III & 19 days & poor & $\begin{array}{l}\text { disturbance of } \\
\text { consciousness }\end{array}$ & primary damage \\
\hline 8 & 63. F & $\mathrm{BA}$ & III & 17 days & poor & $\begin{array}{l}\text { disturbance of } \\
\text { consciousness }\end{array}$ & primary damage \\
\hline 9 & 65. F & BA & IV & 17 days & poor & $\begin{array}{l}\text { disturbance of } \\
\text { consciousness }\end{array}$ & primary damage \\
\hline 10 & 55. F & PICA & IV & 40 days & poor & $\begin{array}{l}\text { disturbance of } \\
\text { consciousness }\end{array}$ & primary damage \\
\hline 11 & 57.M & $\begin{array}{c}\text { VA } \\
\text { (fusiform) }\end{array}$ & Ia & 59 days & $\begin{array}{c}\text { dead } \\
(10 \mathrm{mos})\end{array}$ & rebleeding & $\begin{array}{l}\text { surgical procedure } \\
\text { (proximal clipping) }\end{array}$ \\
\hline 12 & 67. F & $\mathrm{BA}$ & III & 83 days & dead & $\begin{array}{l}\text { disturbance of } \\
\text { consciousness }\end{array}$ & primary damage \\
\hline
\end{tabular}


Table 6 Overall surgical result in cases with ruptured vertebro-basilar aneurysms

\begin{tabular}{ccccccc}
\hline \multirow{2}{*}{$\begin{array}{c}\text { Timing of op. \& } \\
\text { clinical grade }\end{array}$} & \multicolumn{5}{c}{ Overall surgical result } & \multirow{2}{*}{ Total } \\
\cline { 2 - 5 } & Excellent & Good & Fair & Poor & Dead & \\
\hline Within 3 days & $\mathbf{6}$ & $\mathbf{2}$ & $\mathbf{0}$ & $\mathbf{1}$ & $\mathbf{1}$ & $\mathbf{1 0}$ \\
I & 2 & 0 & 0 & 0 & 0 & 2 \\
II & 3 & 1 & 0 & 1 & 0 & 5 \\
III & 1 & 0 & 0 & 0 & 0 & 1 \\
IV & 0 & 1 & 0 & 0 & 1 & 2 \\
4-7 days & $\mathbf{3}$ & $\mathbf{0}$ & $\mathbf{0}$ & $\mathbf{1}$ & $\mathbf{2}$ & $\mathbf{6}$ \\
I & 1 & 0 & 0 & 0 & 0 & 1 \\
III & 2 & 0 & 0 & 1 & 1 & 4 \\
IV & 0 & 0 & 0 & 0 & 1 & 1 \\
8-14 days & $\mathbf{2}$ & $\mathbf{0}$ & $\mathbf{0}$ & $\mathbf{0}$ & $\mathbf{0}$ & $\mathbf{2}$ \\
I & 2 & 0 & 0 & 0 & 0 & 2 \\
Over 15 days & $\mathbf{3 3}$ & $\mathbf{2}$ & $\mathbf{0}$ & $\mathbf{8}$ & $\mathbf{3}$ & $\mathbf{4 6}$ \\
I & 24 & 0 & 0 & 2 & 1 & 27 \\
Ia & 6 & 2 & 0 & 2 & 1 & 11 \\
III & 2 & 0 & 0 & 2 & 1 & 5 \\
IV & 1 & 0 & 0 & 2 & 0 & 3 \\
\hline Total & $44(69 \%)$ & $4(6 \%)$ & 0 & $10(16 \%)$ & $6(9 \%)$ & 64 \\
\hline
\end{tabular}

Table 7 Causative factors of disability and death in cases with ruptured vertebro-basilar aneurysms

\begin{tabular}{ccccc}
\hline \multirow{2}{*}{\begin{tabular}{c} 
Timing of op. \& $\begin{array}{c}c \\
\text { clinical grade }\end{array}$ \\
\cline { 2 - 4 }
\end{tabular}} & $\begin{array}{c}\text { N.D.before } \\
\text { operation }\end{array}$ & $\begin{array}{c}\text { Surgical } \\
\text { procedure }\end{array}$ & $\begin{array}{c}\text { Vaso- } \\
\text { spasms }\end{array}$ & \\
\hline Within 3 days & $\mathbf{1}$ & $\mathbf{1}$ & $\mathbf{0}$ & $\mathbf{2}$ \\
I & 0 & 0 & 0 & 0 \\
II & 0 & 1 & 0 & 1 \\
III & 0 & 0 & 0 & 0 \\
IV & 1 & 0 & 0 & 1 \\
4-7 days & $\mathbf{1}$ & $\mathbf{0}$ & $\mathbf{2}$ & $\mathbf{3}$ \\
I & 0 & 0 & 0 & 0 \\
III & 1 & 0 & 1 & 2 \\
IV & 0 & 0 & 1 & 1 \\
8-14 days & $\mathbf{0}$ & $\mathbf{0}$ & $\mathbf{0}$ & $\mathbf{0}$ \\
Over 15 days & $\mathbf{7}$ & $\mathbf{3}$ & $\mathbf{1}$ & $\mathbf{1 1}$ \\
I & 0 & 2 & 1 & 3 \\
Ia & 2 & 1 & 0 & 3 \\
III & 3 & 0 & 0 & 3 \\
IV & 2 & 0 & 0 & 2 \\
\hline Total & $9(56 \%)$ & $4(25 \%)$ & $3(19 \%)$ & 16 \\
\hline
\end{tabular}

の fusiform AN で手術操作による悪化が認められたのみ であり，急性期手術例でも結果不良例は術前状態の悪い例
が大部分を占め, 手術操作そのものの影響は少なかった. 結局, 出血後 7 日以内手術例のうち grade I, II の例で は, VA fusiform AN を除きすべて結果良好であり，例数 は少ないが grade III, Nでも他部位動脈瘤に比べやや成績 が覀い程度で, VB AN の慢性期手術例の成績には劣って おらず, Peerlessらの報告 ${ }^{5)}$ と同じ傾向を示した。

またわれわれの成績は, Bottrell の grade I, IIでは excellent, good が86\%, III, IVでは54\%であった Peerless らの 成績 ${ }^{5)}$ と比較すると, 後者では例数が少なく比較できない が, Battrell I， II に相当する Hunt らの grade I 〜 II で は, VA fusiform AN を除く 12 例中 10 例 $(83 \%)$ が excellent, good であり，ほほ同様の成績であった。

以上述べてきた事柄に，4〜 7 日手術例に比べ 3 日以内 手術例の成績が良いこと, および手術待機中の再出血によ る悪化・死亡が高率であること年6) を考え併せると, VA fusiform AN を除くVB ANでも, 他部位動脈瘤同様, 出 血後可及的早期に手術を行うことにより，治療成績が向上 すると思われる。

$$
\text { まとめ }
$$

自験例での手術成績の検討から, 破裂椎骨脳底動脈瘤で も, VA fusiform AN を除けば, 他部位脳動脈瘤と同様, 出血後可及的早期に手術を行う必要があると考えられる. 
Table 8 Overall surgical result in cases with ruptured cerebral aneurysms

\begin{tabular}{|c|c|c|c|c|c|c|c|}
\hline \multirow{2}{*}{\multicolumn{2}{|c|}{$\begin{array}{l}\text { Timing of the } \\
\text { operation }\end{array}$}} & \multicolumn{5}{|c|}{ Overall surgical result } & \multirow{2}{*}{ Total } \\
\hline & & Excellent & Good & Fair & Poor & Dead & \\
\hline \multicolumn{2}{|l|}{$\begin{array}{l}\text { Posterior } \\
\text { circulation }\end{array}$} & $44(69 \%)$ & $4(6 \%)$ & $\mathbf{0}$ & $10(16 \%)$ & $6(9 \%)$ & 64 \\
\hline Within 3 & days & $6(60 \%)$ & $2(20 \%)$ & 0 & $1(10 \%)$ & $1(10 \%)$ & 10 \\
\hline $4-7$ & days & $3(50 \%)$ & 0 & 0 & $1(17 \%)$ & $2(33 \%)$ & 6 \\
\hline $8-14$ & days & $2(100 \%)$ & 0 & 0 & 0 & 0 & 2 \\
\hline Over 15 & days & $33(72 \%)$ & $2(4 \%)$ & 0 & $8(17 \%)$ & $3(7 \%)$ & 46 \\
\hline \multicolumn{2}{|l|}{$\begin{array}{l}\text { Anterior } \\
\text { circulation }\end{array}$} & 404( $79 \%)$ & $24(5 \%)$ & $22(4 \%)$ & $19(4 \%)$ & $45(9 \%)$ & 514 \\
\hline Within 3 & days & $124(66 \%)$ & $10(5 \%)$ & $14(7 \%)$ & $9(5 \%)$ & $31(16 \%)$ & 188 \\
\hline $4-7$ & days & $34(87 \%)$ & $2(5 \%)$ & 0 & $1(3 \%)$ & $1(3 \%)$ & 38 \\
\hline $8-14$ & days & $48(87 \%)$ & $1(2 \%)$ & 0 & $1(2 \%)$ & $5(9 \%)$ & 55 \\
\hline Over 15 & days & $198(85 \%)$ & $11(5 \%)$ & $8(3 \%)$ & $8(3 \%)$ & $8(3 \%)$ & 233 \\
\hline \multicolumn{2}{|c|}{ Total } & $448(78 \%)$ & $28(5 \%)$ & $22(4 \%)$ & $29(5 \%)$ & $51(9 \%)$ & 578 \\
\hline
\end{tabular}

\section{文献}

1) Drake CG: The treatment of aneurysms of the posterior circulation. Clin Neurosurg 26: 96-144, 1978

2）柿沢敏之, 三塚 繁, 金子的実，ほか：内頸動脈閉塞に同 側後大脳動脈後交通動脈分岐部動脈瘤を伴った 2 例. 脳卒 中の外科 16: $53-58,1988$

3) Locksley HB: Natural history of subarachnoid hemorrhage. In: Sah AL, Perret GE, Locksley HB, et al (eds), Intracranial Aneurysms and Subarachnoid Hemorrhage, Lippincott, Philadelphia, 1969, pp 37-108

4) Pia HW: Vertebro-basilar aneurysms. In: Pia HW, Langmaid C, Zierski J (eds), Cerebral Aneurysms. Advances in Diagnosis and Therapy, Springer-Verlag, Berlin-Heidelberg-New York, 1979, pp 306-311
5) Peerless SJ, Nemoto S, Drake CG: Acute surgery for ruptured posterior circulation aneurysms. In: Symon L, Brihaye J, Cohadon F, et al (eds), Advances and Technical Standards in Neurosurgery, Vol. 15, Springer-Verlag, WienNew York, 1987, pp 115-129

6) Sundt TM, Kobayashi S, Fode NC, et al: Results and complications of surgical management of 809 intracranial aneurysms in 722 cases. J Neurosurg 56: 753-765, 1982

7) Troupp H: The natural history of aneurysms of the basilar bifurcation. Acta Neural Scand 47: 350-356, 1971

8) 山浦 晶：椎骨脳底動脈瘤の手術. Pitfalls and complications. Neurosurgeons 4: 375-383, 1984

9) Yasargil MG: Microneurosurgery 2, George Thieme Verlag, Stuttgart, New York, 1984 